\title{
Contextualização e o Ensino de Matemática: uma análise das questões de matemática do vestibular da UEPA
}

Contextualization and math education: an analysis of issues of UEPA vestibular math

\author{
Andrey Patrick Monteiro de Paula ${ }^{1}$ \\ Francilena de Oliveira Caldas ${ }^{2}$ \\ Marcionílio Costa da Silva ${ }^{3}$ \\ Maria Berenice Gomes da Silva de Paula ${ }^{4}$
}

\section{Resumo}

A referida pesquisa tem como objetivo identificar e caracterizar as estratégias de contextualização utilizadas pela Universidade do Estado do Pará - UEPA, nas questões de matemática em seu processo seletivo (Prosel), no período de 2011 a 2015. No entanto,foi analisado, de acordo com Bardin (2009), o enunciado de 100 questões de matemática. Neste contexto, identificaram-se seis grupos de estratégias utilizadas pela UEPA, sendo estas: Contextualização nas práticas sociais atuais; Contextualização em outras áreas do conhecimento; Contextualização na própria matemática; Contextualização na história da matemática; Contextualização em características regionais e "Pré-textualização" e/ou Pseudocontextualização. A estratégia que buscou aproximar os conhecimentos matemáticos com as práticas sociais atuais teve maior evidência (47\%), em detrimento da busca por relação das características regionais no contexto das questões de matemática (6\%). Além disso, observou-se que as estratégias aqui evidenciadas possibilita aos professores compreender de forma mais abrangente a contextualização no ensino de matemática.

Palavras-chave: Universidade do Estado do Pará; Ensino de matemática; Contextualização

\footnotetext{
${ }^{1}$ Mestre em Educação; Docente; Universidade Federal do Tocantins; andrey.depaula@uft.edu.br.

${ }^{2}$ Licenciada em Matemática; Especialista em Educação Matemática; Universidade do Estado do Pará; francycaudas@hotmail.com.

${ }^{3}$ Licenciado em Matemática; Universidade do Estado do Pará; marceonilio@yahoo.com.br.

${ }^{4}$ Licenciada em Matemática; Especialista em Política de Promoção da Igualdade Racial na Escola; Universidade do Estado do Pará; bere.atm@hotmail.com.
} 


\section{Abstract}

This research has the objective to identify and characterize the contextualization strategies used by the Pará State University - UEPA, in its selective process related to mathematical questions, in the last 5 years, 2011 to 2015. Nevertheless, the enunciated 100 mathematical questions were analyzed in accordance with Bardin (2009). In this context 6 strategic groups, used by UEPA, were identified as follows: Contextualization in the actual social practice; Contextualization in other areas of knowledge; Contextualization in mathematics itself ; Contextualization in the history of mathematics; Contextualization in regional characteristics and "Retextualization" and/or pseudocontextualization. The strategy that sought to bring the mathematical knowledges close to the actual social practice had a great evidence $(47 \%)$ in detriment of the search of regional characteristics relation in the context of mathematical questions (6\%).It is observed also that the strategieshighlightedhere enables the teachers to understand, in a more comprehensive manner, the contextualization in mathematics education.

Key-words: Pará State University; Mathematics education; Contextualization

\section{Introdução}

$\mathrm{Na}$ tentativa de proporcionar e orientar aos professores a tornar o ensino de matemática mais significativo para os alunos, os documentos oficiais que norteiam a educação, como os Parâmetros Curriculares Nacionais, as Orientações Curriculares Complementares aos Parâmetros Curriculares Nacionais do Ensino Médio - PCN + (BRASIL, 2002), Orientações Curriculares para o Ensino Médio - Ocnem (BRASIL, 2006) e as novas Diretrizes Curriculares Nacionais para o Ensino Médio - Dcnem (BRASIL, 2012), consideram a contextualização e a interdisciplinaridade como um eixo organizador, como competência e uma das formas de promover um ensino integrado.

Em vista disso, Kasprzykowski (2014), Souza (2014), Carrocino (2014), Hiane (2011) e Deleprani (2012) atentam ainda mais para o fato de que a abordagem dada à contextualização, seja nos livros didáticos, seja nos documentos, nas provas de vestibulares ou até mesmo em simples atividades realizadas em sala de aula, é, diversas vezes, direcionada apenas em relação da 
matemática com o cotidiano, negligenciando, portanto, fatores como a história, a própria matemática entre outros, ou até mesmo por apresentar questões que apresentam uma falsa contextualização.

Por essas e outras particularidades inerentes à contextualização e a sua importância no ensino aprendizagem de matemática na educação básica, principalmente no século XXI com sua valorização no Exame Nacional do Ensino Médio (ENEM) e devido ao fato destes autores serem alunos egressos da Universidade do Estado do Pará, propõe-se aqui buscar uma resposta para a seguinte questão: como a Universidade do Estado do Pará (UEPA) explorou a contextualização nas questões de matemática de seu processo seletivo (Prosel), no período de 2011 a 2015 ?

\section{Contextualização no ensino de matemática: considerações}

A contextualização, apesar de presente nos discursos dos professores e nos documentos que direcionam a educação no país, ainda causa polêmica e grandes equívocos, isto dificulta vê-la como algo que vai além de mostrar para os alunos onde se "aplicam" os conteúdos da disciplina de matemática. Em vista disso, Brousseau (1996) orienta a se promover uma recontextualização do saber, procurando situações que deem sentido aos conhecimentos a serem ensinados, ao passo que, ao encontrar a solução de um problema, o aluno não consegue ver sua produção como conhecimento, o qual poderá ser utilizado em outras situações. Contudo, é importante transformar esses conhecimentos em saber e, para isso, é necessário, "[...] com a ajuda do professor, "re-despersonalizar e redescontextualizar o saber que produziu, para poder reconhecer no que fez, algo que tenha caráter universal, um conhecimento cultural reutilizável" (BROUSSEAU, 1996, p. 48).

Esse movimento, em busca de uma contextualização real, mostrando aos alunos que o conhecimento produzido, transformado em saber, poderá ser utilizado em outras situações, é considerado por Pavanello (2004), como o ato de 
problematizar. Neste sentido, segundo o referido autor, contextualizar consiste em apresentar o conteúdo por meio de uma situação problematizadora, capaz de dar sentido aos conhecimentos a serem aprendidos e que proporcione o resgate dos conhecimentos prévios, criando, dessa forma, um contexto que dará significado ao conteúdo, isto é, que os conduza à sua compreensão.

Observa-se também que esse movimento considerado por Brousseau (1996) e Pavanellho (2004) corrobora com os Parâmetros Curriculares Nacionais (BRASIL, 1998), nos quais se admite o conhecimento cultural reutilizável, desde o ensino fundamental, pois, "[...] um conhecimento só é pleno se for mobilizado em situações diferentes daquelas que serviram para lhe dar origem. Para que sejam transferíveis a novas situações e generalizados, os conhecimentos devem ser descontextualizados, para serem novamente contextualizados em outras situações." (BRASIL, 1998, p. 36).

Essa relação estende-se aos demais documentos ${ }^{5}$, que objetivam orientar a educação no país, como as orientações curriculares nacionais do ensino médio - Ocnem (BRASIL, 2006), as novas diretrizes curriculares nacionais do ensino médio - Dcnem (BRASIL, 2012) e o guia de livros didáticos de matemática do ensino médio, conforme o plano nacional do livro didático de 2015 (BRASIL, 2014), que contemplam em suas propostas um ensino pautado na interdisciplinaridade e contextualização. Nas Dcnem (BRASIL, 2012), a contextualização vem associada à interdisciplinaridade, considerando-a como uma proposta de termos um ensino de matemática mais amplo englobando o cidadão e a realidade escolar dos alunos. Os Pcnem (BRASIL, 2000) não só consideram a contextualização e a interdisciplinaridade como possibilidade de conexões entre os conceitos e pensamentos matemáticos, assim como o contexto cultural e suas aplicações dentro e fora da matemática e a sua importância histórica no desenvolvimento da própria ciência. Nessa perspectiva, as Ocnem (BRASIL, 2006), ao reforçar o caráter integrador da contextualização, alerta para que a contextualização não apareça simplesmente como uma forma de "ilustrar" o

\footnotetext{
${ }^{5}$ Citam-se aqui apenas os documentos aos quais serão remetidos no decorrer deste trabalho.
} 
enunciado de um problema, mas como uma maneira de dar sentido ao conhecimento matemático na escola.

A ênfase dada à contextualização refletiu nas práticas pedagógicas dos professores em sala de aula, nas políticas de valorização dos livros didáticos e, timidamente, foi sendo valorizada nos processos seletivos de entradas nos cursos de graduação das universidades do Brasil, ganhando mais força com a criação do ENEM, em 1998. Tendo sido, no entanto, reforçada ainda mais a partir de 2009, quando o ENEM passou por um processo de reformulação, considerado aqui como um novo ENEM.

Desde então, as questões de matemática do ENEM e dos vestibulares do Brasil têm sido alvo de observações e análises a fim de investigarem a coerência entre os documentos oficiais referentes à contextualizaçãoe a sua utilização efetiva, no âmbito do ensino das disciplinas escolares, como abordado nas pesquisas de Kasprzykowski (2014), Sousa (2014), Carrocino (2014), Hiane (2011) e Deleprani (2012).

A partir das discussões legais e de pesquisas realizadas até o momento, considera-se a contextualização em seu caráter mais amplo, capaz de dar sentido ao conhecimento matemático em um processo de recontextualização, sem desmerecer a importância dada à relação contextualização e cotidiano. Além disso, considera-se para esta pesquisa a sua relação com a história da matemática, com a interdisciplinaridade, com as práticas sociais, com outras áreas do conhecimento, com a própria matemática e a contextualização referente às características regionais.

\section{Contextualizando a pesquisa}

Para alcançar o objetivo proposto por esta pesquisa, foram analisadas as provas do vestibular da UEPA dos últimos cinco anos, de 2011 a 2015, cujo 
processo seletivo correspondia ${ }^{6}$ ao seu vestibular tradicional. Constituía-se de três etapas realizadas no mesmo ano, as quais exploravam conteúdos específicos de cada ano do ensino médio, por exemplo, a prova da primeira etapa, correspondia aos conteúdos estudados no primeiro ano do ensino médio e assim sucessivamente. Desse modo, quinze provas no geral foram analisadas contemplando as etapas propostas pela UEPA/Prosel no decorrer do ano letivo, sendo assim a primeira e a segunda etapas, correspondendo respectivamente aos conteúdos do primeiro e segundo anos do ensino médio, eram compostas de sete questões de matemática cada uma; enquanto a terceira etapa correspondia ao terceiro ano do ensino médio e contava com seis questões de matemática, obtendo-se um total de 20 questões de matemática por ano e um total de 100 questões de matemática do período estudado. De um modo mais detalhado, foram analisados 35 questões de matemática na primeira etapa, 35 questões na segunda etapa e 30 questões na terceira etapa.

Considerando as 100 questões de matemática, distribuídas em três etapas, optou-se pela técnica de análise de conteúdo por proporcionar um estudo sistemático e objetivo dos conteúdos explorados nas mensagens, possibilitando obter indicadores (quantitativos ou não) que permitem a inferência de conhecimentos relativos às condições de produção e de recepção (variáveis inferidas) destas mensagens (BARDIN, 2009). Esse caráter objetivo da análise de conteúdo propiciou um olhar diferenciado para as questões, que se desencadeou, conforme Bardin (2009), na categorização destas que consistem "essencialmente de operações de codificação, desconto ou enumeração em função de regras previamente reformuladas." (BARDIN, 2009, p.127).

A seguir serão abordados quais os critérios utilizados para incluir as questões em suas determinadas categorias.

\footnotetext{
${ }^{6} \mathrm{~A}$ utilização dos verbos no tempo pretérito, como, por exemplo, "correspondia" se faz referência a notícia em que a UEPA adotaria o ENEM para ingresso dos alunos a partir de 2016.Disponível em:http://www.uepa.br/portal/ascom/ler detalhe.php?id noticia=1863350.
} 


\section{Descrição e análise dos dados}

A descrição baseia-se na terceira etapa proposta por Bardin (2009), a qual trata dos resultados, inferência e interpretação, formando categorias de acordo com os critérios previamente estudados e utilizados para o agrupamento das questões. Respeitando as ideias da referida autora, levam-se também em conta os documentos oficiais, responsáveis pelo direcionamento da educação brasileira (BRASIL 2000; 2002; 2006; 2012) e outras pesquisas referentes à contextualização no ensino de matemática. Assim, evidenciam-se seis categorias de análise: Contextualizações nas práticas sociais atuais; Contextualizações em outras áreas do conhecimento; Contextualizações na própria matemática; Contextualização na história da matemática; Contextualização em características regionais e "Pré-textualização" e/ou Pseudocontextualização.

\subsection{Contextualizações nas práticas sociais atuais}

A contextualização, por buscar dar um significado para a o ensino de matemática, expande-se além de sua relação com o cotidiano dos alunos e proporciona aproximações com o contexto e a realidade social, conforme o PNLD 2015 (BRASIL, 2014). Um dos aspectos distintivos a serem considerados para o ensino da matemática reside na busca de contextos tanto nas práticas sociais do cotidiano, tais como: compras e vendas, empréstimos, crediário, contas bancárias, seguros e tantas outras quanto nas atividades científicas ou tecnológicas. Essa relação foi evidenciada nas provas, uma vez que a maioria das questões, 47 questões, ou seja, $47 \%$ a valorizaram em seu contexto, como pode ser visto no gráfico 1. Como exemplo, observa-se a questão 32, da primeira etapa de 2015 . 
Segundo a Organização das Nações Unidas (ONU), população daTerra atingiuamarcade 7,2 bilhões de habitantes em 2013, dados publicados no estudo "Perspectivas de População Mundial". De acordo com as projeções de crescimento demográfico, seremos 8,1 bilhões de habitantes em 2025 e 9,6 bilhões de habitantes em 2050. Supondo que a partirde 2025 a população mundial crescerá linearmente, a expressão que representará o totalde habitantes $(H)$,embilhões de pessoas, em função do número de anos (A) é: a) $H=0,060 . A+8,1 b$ ) $\mathrm{H}=0,036 . A+7,2 \mathrm{c}) \mathrm{H}=0,060 . A+9,6 \mathrm{~d}) \mathrm{H}=0,036 . \mathrm{A}+8,1 \mathrm{e}) \mathrm{H}=0,060 . \mathrm{A}+7,2$

Considerando essa relação e em consonância com Hiane (2011) e Vieira (2004), identificam-se, para este contexto, as questões de matemática que buscaram fazer relações, além das citadas pelo PNLD de 2015, com os temas transversais como saúde, consumo, trabalho, meio ambiente, reciclagem, decomposição de alimentos, crescimento populacional, ética, política a fim de estimular a autonomia do aluno para a formação da cidadania. $\mathrm{O}$ resultado pode ser visto no gráfico a seguir.

Gráfico 1 - Contextualização nas práticas sociais atuais/UEPA (2011 - 2015)

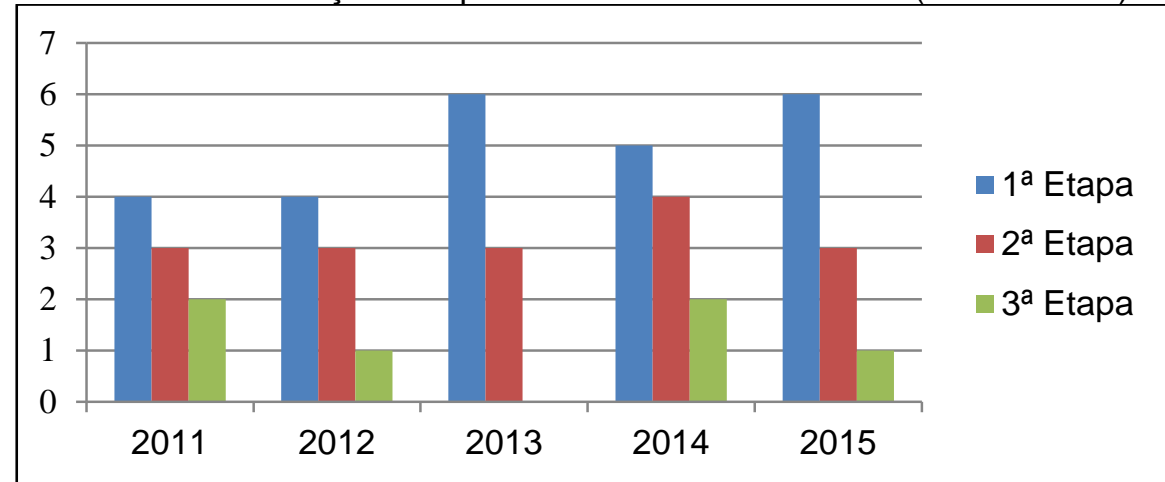

Ao se observar o gráfico 1, percebe-se a presença da contextualização nas práticas sociais atuais nas provas de matemática da UEPA. Dentre esta valorização, a maior frequência ocorreu nas provas correspondentes à primeira etapa. Credita-se este fato à valorização do conteúdo de função, o qual também é evidenciado por Rodrigues (2013), ao analisar as questões de matemática das provas do ENEM (2009 - 2012) e os livros didáticos do ensino médio, conforme PNLD de 2015 (BRASIL, 2014) e por considerar que o aluno deva saber lidar com o conceito de função em situações diversas e, neste sentido, através de uma 
variedade de situações-problema de matemática e, inclusive, de outras áreas (BRASIL, 2000).

Dentre as práticas sociais atuais, aqui consideradas e direcionadas pelos temas transversais e pelo PNLD (2015), identificou-se maior ênfase na relação da matemática com as atividades de consumo, tendo no total 13 questões, como a $29^{\underline{a}}$ e a $30^{\underline{a}}$ da primeira etapa de 2013 e a $26^{\underline{a}}$ questão da terceira etapa de 2014; questões relacionadas ao meio ambiente também tiveram destaque, tendo no total oito questões, como a $29^{\mathrm{a}}$, a $32^{\mathrm{a}}$ e a $33^{\mathrm{a}}$ questão da primeira etapa de 2011. As questões abordaram ainda uma preocupação com práticas relacionadas à violência doméstica, à violência no trânsito, ao uso das redes sociais, aos aplicativos da internet, ao consumo de drogas, ao bullying, entre outras.

\subsection{Contextualizações em outras áreas do conhecimento}

Explorações de conhecimentos matemáticos em áreas como engenharia, medicina, nutrição, design etc. são amplamente reconhecidos em sua essência para o êxito de estudos e experimentos destas e de outras ciências, podendo também se relacionar com a geografia, física, química, biologia, artes, música, história, astronomia, favorecendo a visão de uma ciência integrada e articulada a diferentes contextos do saber humano, dentro de um enfoque interdisciplinar (HIANE, 2011).

Ao buscar essa relação, pode-se citar, a título de exemplo, a questão $33^{\text {a }}$, da segunda etapa de 2013.

As caminhadas e corridas de rua são atividades incorporadas à cultura esportiva dos brasileiros. Um praticante de corrida popular (cooper) balança cadaumdeseusbraçosritmicamenteenquanto corredeacordocomomodelodadopela expressão:

$f(t)=\frac{\pi}{9} \operatorname{sen}\left[\frac{8 \pi}{3}\left(t-\frac{3}{4}\right)\right]$; onde $f(t)$ é o ângulo compreendido entre a posiçãodo braço e o eixo vertical, e t, tempo em segundos, conformeilustradoabaixo. Nessas condições o maior ângulo obtido com o movimento cíclico do braço do corredor é: (Texto Adaptado:Cálculo para Ciências Médicas e Biológicas. São Paulo: Harbra, 1998).
a) $10^{\circ}$
b) $15^{\circ}$
c) $20^{\circ}$
d) $25^{\circ}$
e) $30^{\circ}$ 
Apesar de várias possibilidades de relações da matemática em contextos diferenciados, apenas $17 \%$ das questões, correspondendo a 17 questões, trouxeram essas características, conforme o gráfico 2.

Gráfico 2 - Contextualização em outras áreas de conhecimento/Análise Prosel/UEPA (2011 2015)

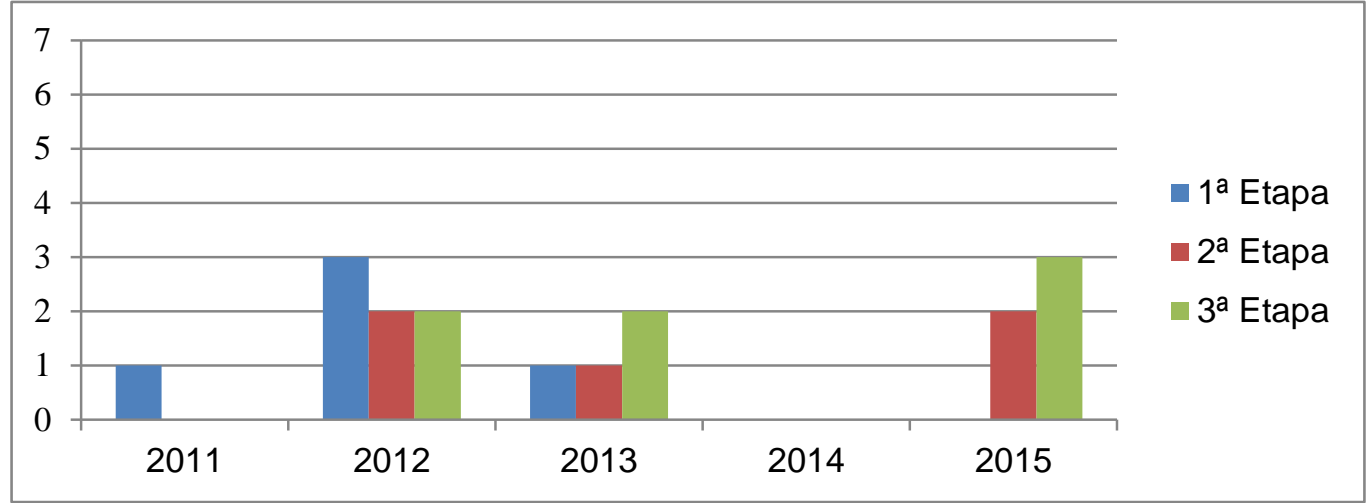

Uma das possibilidades de proporcionar significado ao ensino de matemática está na relação desta com as demais áreas do conhecimento (BRASIL, 2000; 2012), pois "Em um mundo onde as necessidades sociais, culturais e profissionais ganham novos contornos, todas as áreas requerem alguma competência em Matemática [...]" (BRASIL, 2000, p. 40). Ao se analisar os enunciados das questões de matemática da UEPA, observa-se essa relação em contextos que tratam da relação com a física: a 30ª da primeira etapa de 2012 e a $26^{\text {a }}$ da terceira etapa de 2015; educação física: a $29^{\underline{a}}$ da terceira etapa de 2012 e a 33르 da segunda etapa de 2013, dentre outras áreas como saúde, design, biologia, moda, nutrição, artes, paisagismo, informática, agricultura e economia. Convém ressaltar que a terceira etapa teve o menor número de questões contextualizadas nesta categoria ou, por outro lado, nem sequer teve como nos anos de 2011 e 2014. No entanto, o caráter interdisciplinar "não deve ser vista como um produto suplementar a ser oferecido eventualmente se der tempo, porque sem ela o conhecimento desenvolvido pelo aluno estará fragmentado e será ineficaz. (BRASIL, 2002, p. 31). 


\subsection{Contextualizações na própria matemática}

Embora possa parecer um tanto diferente, cabe enfatizar a importância da contextualização, tendo em vista que a matemática por si só carrega consigo variadas possibilidades de contextos de forma a relacionar seus grandes campos de estudos, como geometria e álgebra, geometria e aritmética, possibilitando assim o estudo dos números e operações, apoiados aos conhecimentos geométricos ou vice-versa, consolidando-se como "Um vasto campo para a contextualização dos conceitos e procedimentos matemáticos [...]" (BRASIL, 2010 , p. 76 ). Fato que pode ser verificado na $30^{\text {a }}$ questão da terceira etapa de 2014.

Questão 30 (terceira etapa/2014): Uma empresa que fornece serviço de transporte rápido de São Paulo para Belém dispõe de três tamanhos de caixas para envio de objeto, conforme ilustrado abaixo. O polinômio de variável $\mathrm{x}$, indicado por $\mathrm{C}(\mathrm{x})$ que representa a soma dos volumes das três caixas dessa empresa é:
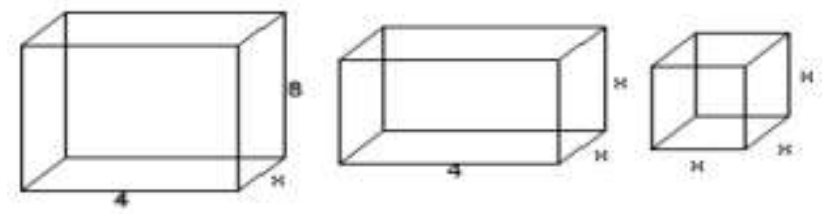

a) $\mathrm{C}(x)=x^{3}+2 x^{2}+x$

b) $\mathrm{C}(x)=x^{3}+4 x^{2}+x$

c) $\mathrm{C}(x)=x^{3}+2 x^{2}+8 x$

d) $\mathrm{C}(x)=x^{3}+2 x^{2}+16 x$

e) $\mathrm{C}(x)=x^{3}+4 x^{2}+32 x$

Em vista das considerações anteriores, incluem-se nesta categoria, as questões que expõem em seus enunciados as relações de aritmética, álgebra e geometria espacial e geometria analítica ou vice-versa, as quais representaram em um total de 100 questões apenas 12\% (doze questões) das questões analisadas, conforme se nota no gráfico 3 
Gráfico 3 - Contextualização com a própria matemática/ Análise Prosel/UEPA (2011 - 2015)

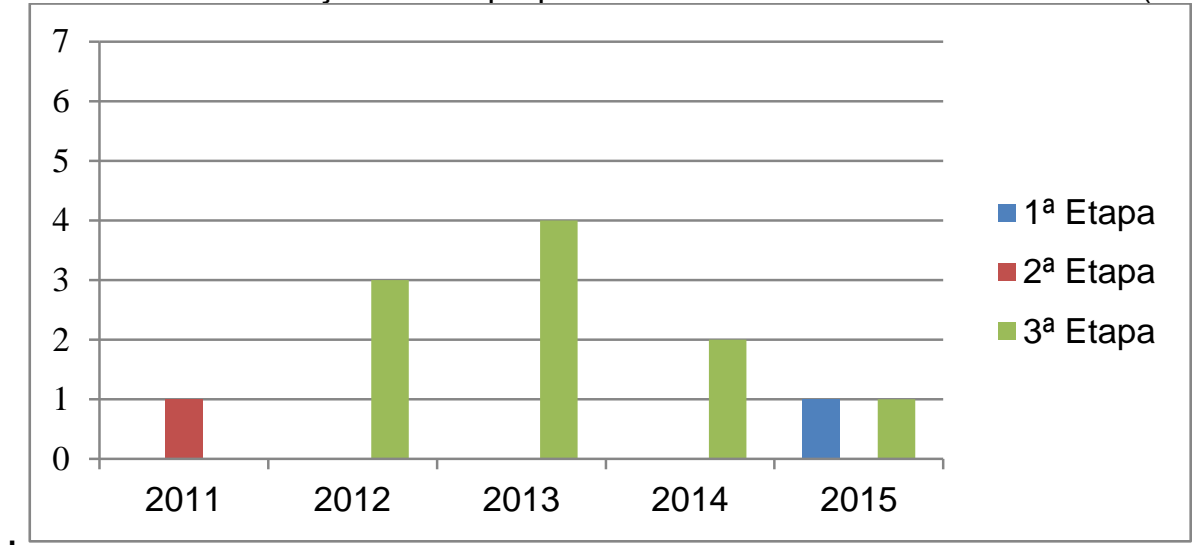

Articular os campos da matemática se propõe como uma possibilidade de contexto desta disciplina (BRASIL, 2000; 2006), em face disso, identifica-se, nas referidas provas, principalmente a relação entre a geometria espacial e a álgebra (gráfico 3) e outras como, por exemplo, a 28루 questão da terceira etapa de 2012 e a 30aㅡ da terceira etapa de 2014, relação da álgebra e geometria analítica como a

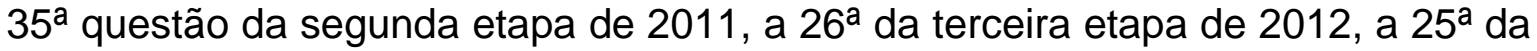
terceira etapa de 2013 e a 27ª da terceira etapa de 2015, além de outras relações como, por exemplo,com a geometria espacial e a analítica com a aritmética.

É importante sobrelevar que a busca por essa significação, considerando o viés aqui mencionado, deve proporcionar o entendimento de figuras geométricas, via equações, e o entendimento de equações, via figuras geométricas, a fim de "estabelecer conexões entre diferentes temas matemáticos e entre esses temas e o conhecimento de outras áreas do currículo".(BRASIL, 2000, p. 77).

\subsection{Contextualização na história da matemática}

A história da matemática serve como uma das possibilidades de se contextualizar o ensino desta disciplina, visto que a matemática de hoje é fruto de muitas evoluções tanto da própria ciência como da sociedade, tornando-se significativa e com um caráter didático para o ensino desta disciplina, pois,em concordância com Miguel; Miorim (2004), o poder da história desempenha um 
processo desmistificador dos conceitos matemáticos, desvendando seu processo de construção e mostrando a matemática como resultado da criação humana em detrimento da maneira cristalizada como, muitas vezes, é apresentada. À guisa de exemplo, a questão 32 da segunda etapa de 2014:

Leia o texto IX para responder à questão 32 Texto IX

As pirâmides comunicam, ainda hoje, os valores culturais de uma das civilizações mais intrigantes da humanidade. Foram construídas para a preservação do corpo do faraó. De acordo com a lenda de Heródoto, as grandes pirâmides foram construídas de tal modo que a área da face era igual ao quadrado da altura da pirâmide.

(Texto adaptado: Contador, Paulo Roberto Martins. A Matemática na arte e na vida- 2 ed. rev. - São Paulo: Editora Livraria da Física, 2011).

Questão 32a : Considere a pirâmide de base quadrada, cujo lado mede $2 \mathrm{a}$ a altura $\mathrm{H} \mathrm{e}$ a altura da face $\mathrm{h}$, construída segundo a lenda de Heródoto. Se S expressa a área da face da pirâmide, então é correto afirmar que:

a) $\left.\left.S=(a+h) \cdot(a-h) b) S=(h+a) \cdot(h-a) c) S=(a+b)^{2} d\right) S=(h-a)^{2} e\right) S=a^{2} \cdot h^{2}$

Portanto, consideram-se, neste momento, as questões de matemática que fazem referência em seus enunciados a fatos, personagens, informações históricas e problemas matemáticos da antiguidade.

Gráfico 4 - Contextualização na história da matemática/ Análise Prosel/UEPA (2011 - 2015)

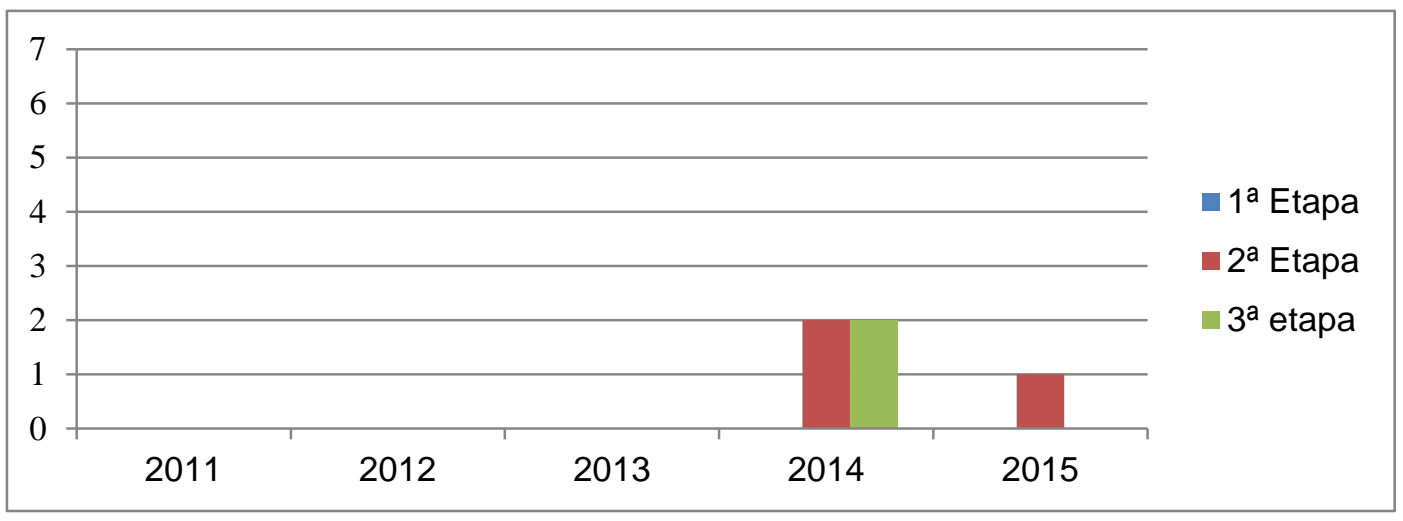

Os dados dispostos no gráfico 4 revelam que, apesar de considerações favoráveis ao uso da história como instrumento de aprendizagem desde o ensino fundamental, como mencionado nos estudos realizados por Miguel; Miorin (2004), reforçado ainda pelos Parâmetros Curriculares Nacionais, foi tímida a relação desta nas provas de vestibulares da UEPA. Por outro lado, no período compreendido de 2011 a 2013, não houve questão com qualquer alusão histórica em seu contexto, enquanto 2014 foi o ano em que teve maior ocorrência desse 
tipo de questão, sendo estas a $32^{\underline{a}}$ e a $33^{\underline{a}}$ da segunda etapa e a $28^{\underline{a}}$ e a $29^{\underline{a}}$ da terceira etapa de 2014. No ano de 2015, apenas a 34르 questão da segunda etapa abordou o tema. Contudo, apenas $5 \%$ das questões, que corresponde a cinco questões, abordaram a história da matemática em seus enunciados, numa perspectiva pautada em sua maioria em história-informação, conforme Matos, Silva e Paula (2012).

\subsection{Contextualização em características regionais}

A Lei n‥ 9.394, a LDB (BRASIL, 1996), em seu artigo 26, ao tratar da parte diversificada do currículo, orienta a valorização do estudo das características regionais e locais da sociedade, da cultura, da economia e da comunidade acadêmica, independente do ciclo da vida no qual os sujeitos tenham acesso à escola. Considerando que este fato reflete diretamente nos Projetos Políticos Pedagógicos (PPP) das escolas assim como nos Projetos Pedagógicos dos Cursos de Graduação (PPC) e nos PCN, das diversas áreas de conhecimentos, é oportuno saber como a UEPA tratou do contexto característico do Estado do Pará em suas questões de matemática. Nesse viés, pode se tomar como exemplo a questão 28 da terceira etapa de 2011.

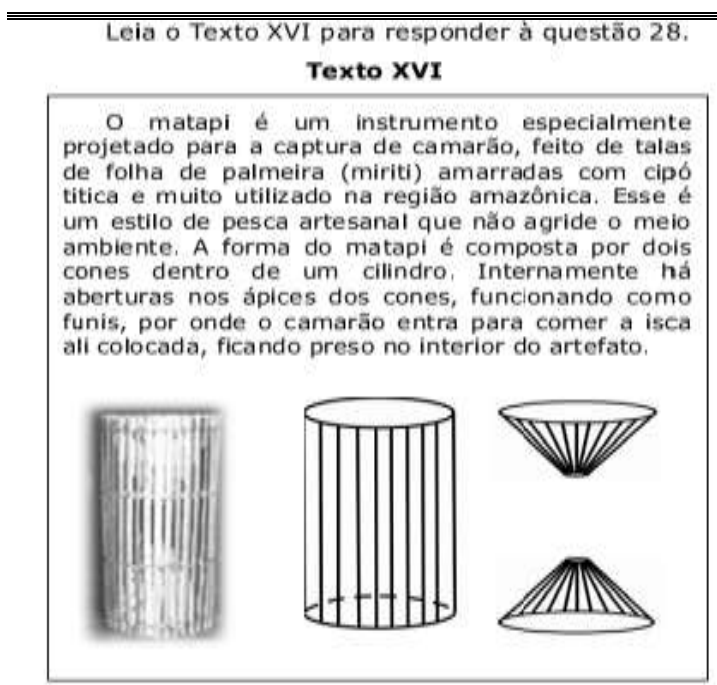

Questão 28: Considere, com as necessárias e devidas aproximações, que a altura de um cone é $1 / 3$ da altura do cilindro e que os raios dessas duas figuras são iguais. Desse modo, a razão entre o volume do cone e o volume do cilindro é:

a) $1 / 9$ b) $1 / 6$ c) $1 / 3$ d)3 e) 9

No entanto, nesta categoria há questões que trazem para discussão ou reflexão características regionais do Estado do Pará, assim como seus hábitos e 
costumes para fazer relações ou explorar a matemática presente nas manifestações culturais do povo paraense.

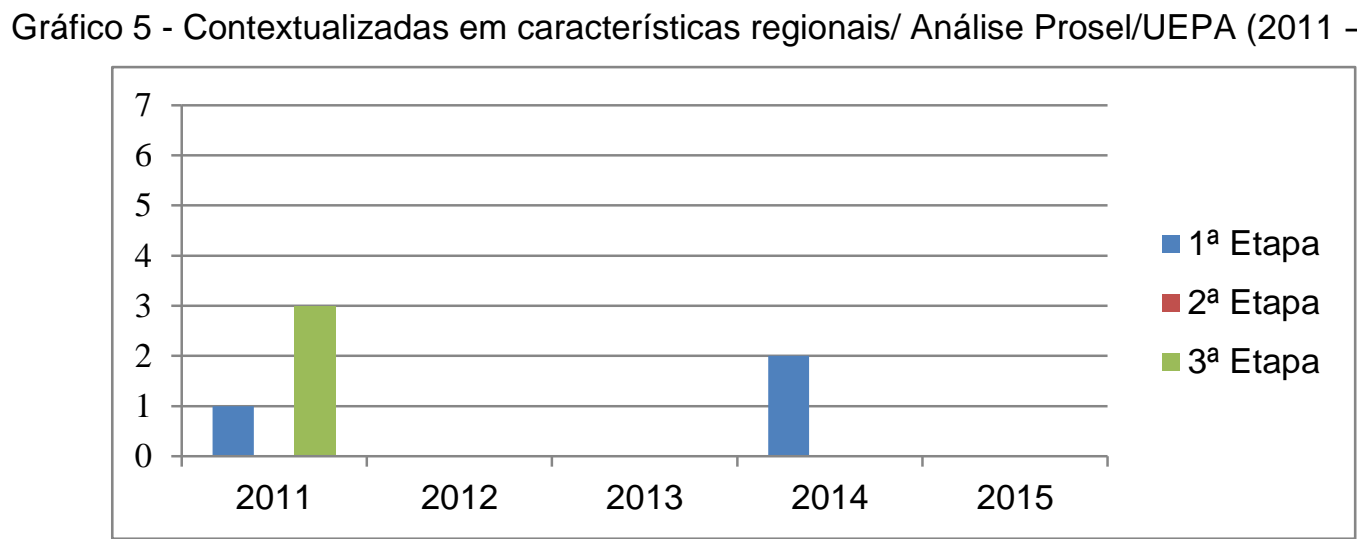

Como se verifica no gráfico 5 , apenas $6 \%$ das questões do vestibular da UEPA trouxeram em seus enunciados referências ao contexto paraense. No entanto, há uma desvalorização da cultura local que pode ser percebida, sobretudo, nos anos 2012, 2013 e 2015 quando não houve nenhuma questão que abordasse a realidade nortista. Dentre as questões que, de alguma forma, trouxeram características paraenses, além da citada, têm-se a questão $30^{\text {a }}$ da

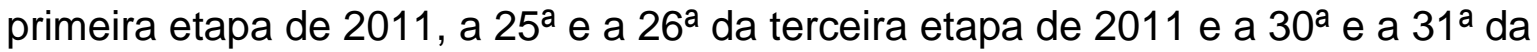
primeira etapa de 2014.

Apesar disso, ressalta-se a importância de resgatar elementos da cultura paraense, na exploração de conhecimentos matemáticos, em especial do pensamento geométrico (MENDES; FERRETE,2003), podendo ser explorado em ornamentos presentes na cerâmica amazônica, em especial a marajoara e a icoaraciense, peculiares do Estado do Pará, dentre outros.

\section{6 "Pré-textualização" e/ou Pseudocontextualização}

A preocupação em ter a todo custo a contextualização nas aulas e nas avaliações em matemática, leva, muitas vezes, à aplicação forçada de contextos irreais. Diante disso, opera-se o que pode ser conceituado como uma pseudocontextualização (HIANE, 2011). Desse modo, as situações que, 
pretensamente, envolvem algum contexto, mas que, de fato, retratam algo irreal e servem apenas como pretexto para a apresentação de dados. Nesta mesma direção, define-se como "pré-textualização", conforme Homero (2014), as questões que antes objetivas são, forçadamente, direcionadas a terem certo contexto, a ser manipulado pelos alunos e podem até mesmo ser consideradas como contextualizações artificiais, segundo as perspectivas de Skovsmose (2000). Como exemplo disso, cabe citar a questão 31 da primeira etapa de 2011.

Supondo que um restaurante com um ano de existência jogue fora no lixo certa quantidade de comida da seguinte forma: no $1^{\circ}$ mês, $2 \mathrm{~kg}$; no $2^{\circ}$ mês, $4 \mathrm{~kg}$; no $3^{\circ}$ mês, $6 \mathrm{~kg}$ e assim por diante. A quantidade total de comida jogada no lixo pelo restaurante durante esse ano foi de:a) $90 \mathrm{kgb}) 130$ kgc) $156 \mathrm{kgd}) 160 \mathrm{kge}) 178 \mathrm{~kg}$

Considerando que um restaurante, mesmo em fase inicial, produza mais de dois quilos de comida a serem jogados fora por mês, enquadra-se esta questão nesta categoria, por considerá-la irreal em seu contexto. No entanto, as questões classificadas dessa forma são identificadas por apresentarem explicitamente características como essa, e as inicialmente citadas. Vale lembrar que as interpretações podem variar de autor para autor.

Gráfico 6 - "Pré-textualização" e/ou Pseudocontextualização/ Análise Prosel/UEPA (2011 - 2015)

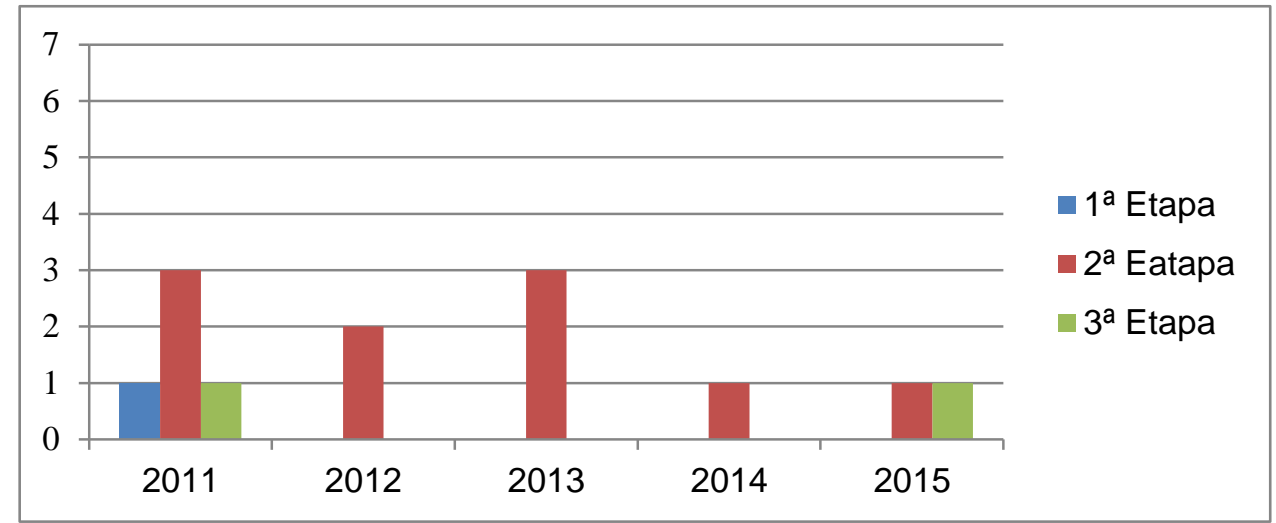

Neste contexto, observa-se certa frequência deste tipo de questão nas provas da UEPA, 13\%, nas quais é visível que, em todos os anos, em pelo menos uma das etapas, houve a presença deste tipo de questão no referido processo seletivo. Além da citada, tiveram tal característica: a $29^{\underline{a}}$, a $30^{\underline{a}}$ e a $31^{\underline{a}}$ da 


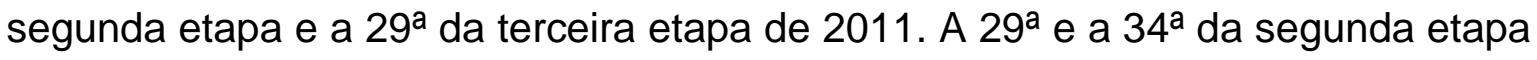
de 2012; a 30를 a $34^{\mathrm{a}}$ e a $35^{\mathrm{a}}$ questões da segunda etapa de 2013; a $35^{\mathrm{a}}$ questão da segunda etapa de 2014; a $30^{\underline{a}}$ questão da segunda etapa e a $28^{\underline{a}}$ da terceira etapa de 2015.

Fugir da referência à matemática pura, de acordo com Skovsmose (2000), na qual predomina os exercícios sem nenhuma relação com elementos que estejam além da matemática, pode ser expresso da seguinte forma: (27a - 14b) + $(23 a+5 b)-11 a=;(16 \times 25)-(18 \times 23)=;(32 \times 41)-(34 \times 39)="$, consiste em um dos entraves que leva a contextualizações irreais no ensino da matemática, pelo simples fato de achar que toda questão deva ser contextualizada, conforme preconizado com o advento do ENEM, fazendo com que certos conteúdos como produtos notáveis, polinômios, radicais e números complexos estejam ausentes dos processos seletivos e das avaliações em larga escala, simplesmente por não serem tão simples de contextualizar.

\section{Considerações finais}

Considerando o objetivo de identificar e caracterizar as estratégias de contextualização utilizadas pela Universidade do Estado do Pará, nas questões de matemática de seu processo seletivo dos últimos cinco anos, de 2011 a 2015, foram consideradas seis estratégias de contextualização (práticas sociais atuais; outras áreas do conhecimento; própria matemática; história da matemática; características regionais e "pré-textualização" e/ou pseudocontextualização).

As estratégias, no entanto, buscaram aproximações com os documentos oficiais que norteiam a educação, uma vez que a proposta de contextualização os perpassa como mais uma forma de dar significado à matemática e de aproximar a vida social dos alunos com o aprendizado da disciplina visando prepará-los tanto para o exercício da cidadania como para o mercado de trabalho.

A abordagem que relaciona a contextualização com as práticas sociais e com outras áreas do conhecimento tiveram grande destaque nos últimos 
processos seletivos desta instituição. Este fato não só se encontra diretamente relacionado com a valorização do Exame Nacional do Ensino Médio, bem como com a preocupação de relacionar a matemática com o cotidiano dos alunos, sendo este considerado, na maioria das vezes, o primeiro viés a se contextualizar.

Características regionais e locais representam um dos componentes a serem contemplados na parte diversificada do currículo da educação básica, no entanto, essa valorização tem ocorrido de forma bastante tímida no vestibular da UEPA, embora, no período em questão, houvesse tido um processo seletivo regional, imerso em um contexto singular com grande potencial de explorações matemáticas, principalmente em uma abordagem etnomatemática explorando conhecimentos geométricos e saberes experienciais de povos culturamente distintos.

Dessa forma, observa-se que a UEPA procurou utilizar várias estratégias de abordagem contextualizada, a fim de atuar com coerência com os documentos oficias, contudo, ainda apresentou questões que promoviam uma pseudocontextualização, tendo sido um total de $13 \%$. A significância dada a esta estratégia está diretamente relacionada à falsa concepção de que toda questão de matemática deva ser contextualizada, sobretudo com o cotidiano do aluno, fato que acaba por privilegiar certos conteúdos, como conhecimentos relativos a funções, em detrimento de outros, como o estudo dos números complexos. Além disso, considera-se que nos estudos, como os de Souza (2014), essa característica é abordada por livros didáticos de matemática adotados pelos professores em sua prática pedagógica.

As questões e observações levantadas pretendem contribuir para ampliar a ideia de um ensino de matemática contextualizado que se tem desencadeado cada vez mais na educação básica e principalmente na disciplina de matemática, e pode, portanto, auxiliar no planejamento das atividades didáticas a serem desenvolvidas em sala de aula, assim como desmistificar o viés de que a contextualização no ensino de matemática está restrita exclusivamente ao cotidiano dos alunos. 
Além de alertar para a valorização das questões de matemática de vestibulares e dos ENEMs, servindo como concretos bancos de dados de problemas de matemática diversificados, possibilitando pesquisas como estaeexplorações didáticas nas aulas dematemática no ensino médio.

\section{Referências}

BRASIL. Lei 9.394 - LDB - Lei das Diretrizes e Bases da Educação, de 20 de dezembro de 1996. Brasília: MEC, 1996.

Ministério da Educação. Secretaria de Educação Fundamental. Parâmetros curriculares nacionais: Ensino fundamental. Brasília: MEC/SEF, 1998.

Ministério da Educação. Secretaria de Educação. Parâmetros curriculares nacionais do Ensino Médio. Brasília: MEC/SEF, 2000.

PCN + orientações educacionais complementares aos parâmetros curriculares nacionais - ensino médio: ciências da natureza, matemática e suas tecnologias. Brasília: MEC, 2002.

. Ministério da Educação. Orientações curriculares para o ensino médio: Ciências da natureza, matemática e suas tecnologias. Brasília: MEC/SEF, 2006.

. Ministério da Educação. Conselho Nacional de Educação. Câmara de Educação Básica. Resolução no 2, de 30 de janeiro de 2012: Define diretrizes curriculares nacionais para o ensino médio. Brasília: CNE, 30 jan. 2012.

Ministério da Educação. Secretaria de Educação Básica II.Guiadelivros didáticos, PNLD/2015. Brasília: MEC/SEF, 2014.

BARDIN, Laurence. Análise de conteúdo. Tradução Luís Antero Reto eAugusto Pinheiro. 4. ed. Lisboa: Edições 70, 2009.

BROUSSEAU, Guy. Os diferentes papéis do professor. In. PARRA, C., SAIZ, I. (Org.). Didática da matemática: reflexões psicopedagógicas. Porto Alegre: Artes médicas, 1996, p. 3-10.

CARROCINO, Carlos Homero Gonçalves. Questões contextualizadas nas provas de matemática. 2014. 69f. Dissertação (Mestrado Profissional em Matemática - Profmat) Instituto de Matemática Pura e Aplicada (IMPA), Rio de Janeiro, 2014.

DELEPRANI, Márcio. As provas de matemática do ENEM: conteúdos, dificuldades e influencias para o currículo do ensino médio. 2012. 169f. Dissertação (Mestrado em Ensino das Ciências na Educação Básica) - Universidade do Grande Rio Prof. José de Souza Herdy, Duque de Caxias, 2012. 
HIANE, Pedro. Questões de matemática da UFMS e ENEM: uma análise da avaliação por conteúdos e por outras competências.2011. 169f.Dissertação (Mestrado em Educação Matemática) - Universidade Federal de Rio Grande do Sul, Campo Grande, 2012.

KASPRZYKOWSKI, André Gaglianone de Almeida. Análise comparativa da prova de matemática do ENEM e do vestibular da UFRJ. 2014. 66f. Dissertação (Mestrado Profissional em Matemática - Profmat) - Universidade Federal do Riode Janeiro, Rio de Janeiro, 2014.

MENDES, Iram Abreu; FERRETE, Rodrigo Bozi. Investigando a matemática presente nos ornamentos da cerâmica icoaraciense. In: CONGRESSO BRASILEIRO DE ETNOMATEMÁTICA, 2.,2004, Natal. Anais...Natal: EdUFRN,p. 159-165, 2004.

. Investigando a cerâmica marajoara e reorientando a matemática escolar. In: ENCONTRO DE PESQUISA EM EDUCACIONAL DAS REGIÕES NORTE E NORDESTE, 16., 2003, Aracaju. Anais... Aracaju: Editora UFS, 2003.

MIGUEL, Antônio; MIORIN, Maria Ângela. História na educação matemática: propostas e desafios. 1. ed. Belo Horizonte: Autêntica, 2004.

PAVANELLO, Regina Maria. Contextualizar, o que é isso? In. NOGUEIRA, C., BARROS, R. (Org.) Conversas e experiências de quem gosta de ensinar matemática.Maringá: Manoni, 2004. p. 17-27.

RODRIGUES, Márcio. Urel. Análise das questões de matemática do novo enem (2009 á 2012): reflexões para professores de matemática. In. ENCONTRO NACIONAL DE EDUCAÇÃO MATEMÁTICA, 11., 2013, Curitiba. AnaisEletrônicos... Disponível em: <http://sbem.esquiro.kinghost.net/anais/xienem/pdf/1029804id.pdf>. Acesso em: maio 2014.

SKOVSMOSE, Ole. Cenários para investigação. Bolema, Rio Claro, v. 13, n. 14, p. 66$91,2000$.

SOUZA, Naiara Fonseca de.Contextualização no ensino de álgebra.2014. 107f. Dissertação (Mestrado em Educação Matemática) - Universidade Federal de Mato Grosso do Sul, Campo Grande, 2014.

VIEIRA, Glaucia Marcondes. Estratégias de "contextualização" nos livros didáticos de matemática dos ciclos iniciais do ensino fundamental. 2004. 139f. Dissertação (Mestrado em Educação) - Universidade Federal de Minas Gerais, Belo Horizonte, 2014. 